\title{
Article \\ Arabidopsis PII Proteins Form Characteristic Foci in Chloroplasts Indicating Novel Properties in Protein Interaction and Degradation
}

\author{
Natalie Krieger ${ }^{1}\left(\mathbb{D}\right.$, Kai-Florian Pastryk ${ }^{1}$, Karl Forchhammer ${ }^{2, *(\mathbb{D})}$ and Üner Kolukisaoglu ${ }^{1, *(D)}$ \\ 1 Center for Molecular Biology of Plants (ZMBP), University of Tübingen, Auf der Morgenstelle 32, \\ 72076 Tübingen, Germany; natalie.krieger@zmbp.uni-tuebingen.de (N.K.); \\ kai-florian.pastryk@student.uni-tuebingen.de (K.-F.P.) \\ 2 Interfaculty Institute of Microbiology and Infection Medicine, University Tübingen (IMIT), \\ Auf der Morgenstelle 28, 72076 Tübingen, Germany \\ * Correspondence: karl.forchhammer@uni-tuebingen.de (K.F.); \\ uener.kolukisaoglu@zmbp.uni-tuebingen.de (Ü.K.); \\ Tel.: +49-7071-29-72096 (K.F.); +49-7071-29-73095 (Ü.K.)
}

check for updates

Citation: Krieger, N.; Pastryk, K.-F.; Forchhammer, K.; Kolukisaoglu, Ü. Arabidopsis PII Proteins Form Characteristic Foci in Chloroplasts Indicating Novel Properties in Protein Interaction and Degradation. Int. J. Mol. Sci. 2021, 22, 12666. https://doi.org/10.3390/ ijms222312666

Academic Editor: Karen Skriver

Received: 7 November 2021

Accepted: 21 November 2021

Published: 23 November 2021

Publisher's Note: MDPI stays neutral with regard to jurisdictional claims in published maps and institutional affiliations.

Copyright: (c) 2021 by the authors. Licensee MDPI, Basel, Switzerland. This article is an open access article distributed under the terms and conditions of the Creative Commons Attribution (CC BY) license (https:// creativecommons.org/licenses/by/ $4.0 /)$

\begin{abstract}
The PII protein is an evolutionary, highly conserved regulatory protein found in both bacteria and higher plants. In bacteria, it modulates the activity of several enzymes, transporters, and regulatory factors by interacting with them and thereby regulating important metabolic hubs, such as carbon/nitrogen homeostasis. More than two decades ago, the PII protein was characterized for the first time in plants, but its physiological role is still not sufficiently resolved. To gain more insights into the function of this protein, we investigated the interaction behavior of AtPII with candidate proteins by BiFC and FRET/FLIM in planta and with GFP/RFP traps in vitro. In the course of these studies, we found that AtPII interacts in chloroplasts with itself as well as with known interactors such as N-acetyl-L-glutamate kinase (NAGK) in dot-like aggregates, which we named PII foci. In these novel protein aggregates, AtPII also interacts with yet unknown partners, which are known to be involved in plastidic protein degradation. Further studies revealed that the C-terminal component of AtPII is crucial for the formation of PII foci. Altogether, the discovery and description of PII foci indicate a novel mode of interaction between PII proteins and other proteins in plants. These findings may represent a new starting point for the elucidation of physiological functions of PII proteins in plants.
\end{abstract}

Keywords: plant PII protein; protein-protein interaction; PII foci; BiFC; FRET/FLIM; plastidic protein degradation; cpUPR

\section{Introduction}

PII signaling proteins are ubiquitously distributed in all prokaryotes and have been conserved in the evolution of the "green lineage". Therefore, PII proteins are found in all plants, from cryptogams to angiosperms, where they are almost exclusively localized in the plastids. In prokaryotes, PII proteins are widely distributed in bacteria and many archaea [1,2]. These trimeric proteins have a highly conserved structure and regulate their targets through tight protein-protein interactions, mainly mediated through a flexible, solvent loop structure of about 18 amino acids, known as the so-called T-loop. The T-loop can adopt various conformations depending on the effector molecules AtP, ADP, or MgATP plus 2-oxoglutarate bound in the three effector binding sites, which are located in the clefts between the subunits. Therefore, the levels of the carbon/nitrogen status-reporter 2-oxoglutarate as well as the energy state, sensed by the AtP to ADP ratio, are integrated by PII. This allows PII to control a multitude of cellular functions, mainly related to nitrogen assimilation, but also to central carbon flux and other core features of metabolism such as NAD-synthesis $[3,4]$. 
In cyanobacteria, which are the phylogenetic ancestors of chloroplasts of the plant kingdom through endosymbiosis, PII signaling has been investigated in detail [5]. The signaling principles are highly conserved compared to heterotrophic bacteria; however, cyanobacteria appear to have evolved specific PII regulatory targets. The controlling enzyme of the arginine pathway, N-acetyl-L-glutamate kinase (NAGK), appears to be a dominant target in these organisms, although recent studies also revealed PII-NAGK interaction in non-photosynthetic bacteria [4]. Moreover, in cyanobacteria, PII controls the flux of newly fixed carbon by controlling a protein that acts as the inhibitor of phosphoglycerate mutase (PGAM) [6].

In 1998, the first plant PII protein was identified and characterized from Arabidopsis. Surprisingly, the amino acid sequence revealed an identity of $50 \%$ or more to homologous protein sequences from E. coli or cyanobacteria [7]. Due to the degree of conservation of PII proteins from bacteria to plants, similar regulatory mechanisms as described above were expected to be mediated by these proteins in plants. Transcription of the corresponding AtPII gene revealed it to be under the control of carbohydrates and nitrogen, indicating a regulatory role of AtPII in $\mathrm{C} / \mathrm{N}$ homeostasis. In further studies, it was reported that plant PII proteins also bind to the NAGK enzyme as in bacteria [8,9]. This interaction has been shown to activate NAGK enzyme activity and to be strictly regulated by different metabolites, such as AtP, 2-oxoglutarate, or glutamine [10-13]. The glutamine dependence was identified in the green alga Chlamydomonas reinhardtii [13] and was resolved to be due to a glutamine-binding C-terminal extension of plant PII proteins. Strikingly, this extension is modified in Arabidopsis thaliana in such a way that AtPII binds NAGK in a glutamine-independent manner. The evolution of glutamine sensing by plant PII proteins was recently reviewed in [14].

Additionally, the interaction of Biotin Carboxyl Carrier Proteins (BCCPs) has been shown for plant PII proteins [12], indicating their regulatory role in fatty acid biosynthesis, which was later found to also occur in bacteria $[15,16]$.

Nevertheless, major physiological phenomena in plants under the control of PII proteins are still waiting to be unraveled. Arabidopsis plants overexpressing AtPII showed enhanced anthocyanin accumulation by glutamine application [7]. This led to the hypothesis of PII in plants as a hub for $\mathrm{C} / \mathrm{N}$ balance, which was supported by the finding of direct glutamine binding of these proteins [13]. In contrast, the phenotype of PII overexpressing plants was unexpectedly moderate. Homologous overexpression of PII in Lotus japonicus led to the deregulation of polyamine content and nodule number under high nitrogen supply [17] as well as the reduction in water loss due to altered stomatal opening [18], but no drastic alteration of plant phenotype has been reported. Furthermore, knock-out and knock-down AtPII plants were phenotypically slightly affected [19]. The utilization of AtPII mutants revealed reduced contents of arginine biosynthesis metabolites under certain nitrogen supply conditions [20] and an increased uptake of nitrite in chloroplasts [21].

Altogether, these findings led to the conclusion that PII is not crucial for plant nitrogen sensing [22]. Instead, it turned out that several proteins, such as the TOR (Target of Rapamycin) kinase, the GCN2 protein kinase, GLRs (glutamate receptor-like proteins), or several other candidates, may have taken over the task of nitrogen sensing in plants (for summaries see $[10,22])$. Among them, the TOR signaling pathway appears to play a central integrative function in this respect [23]. It has been speculated that PII is just responsible for the upregulation of arginine biosynthesis under high glutamine supply [22]. In this case, the question about the function of PII proteins in Arabidopsis and other Brassicaceae would remain, as these proteins had lost their glutamine binding moiety [13].

Moreover, the variety of PII interaction partners in bacteria and plants and the different metabolic pathways regulated by PII in bacteria, together with the degree of PII conservation during evolution, led to the question of whether this protein also plays a more pronounced role in plants. In the present study, we addressed this question by studying the interaction partners and functions of the PII protein in Arabidopsis. During these studies, we observed a specific aggregation behavior of this protein in plastids, leading to the discovery 
of novel interaction partners of AtPII within this suborganellar structure. This specific aggregation behavior pointed to a central role for plant PII proteins in a novel context. Furthermore, we were interested in the mechanism leading to this aggregation, which seems to be mediated by the C-terminal component of the protein.

\section{Results}

\subsection{AtPII Tagged with Fluorescent Proteins Forms Dot-Like Aggregates in Chloroplasts}

The first attempts to analyze the subcellular localization of AtPII revealed that GFPtagged versions of this protein under the control of the $35 \mathrm{~S}$ CaMV-promotor (p35S CaMV::AtPII $\mathrm{I}_{c D N A}-G F P$ ) were found in chloroplasts of transiently transfected tobacco cells. Most interestingly, they appeared as roundly shaped, dot-like or focal aggregates of varying sizes (Figure 1A). To exclude the possibility that these aggregates evolved due to overexpression phenomena, a GFP fusion of the genomic PII sequence driven by its endogenous promotor ( $p$ AtPII::AtPII genomic $-G F P$ ) was introduced into tobacco cells. The expression of this construct also showed plastidial aggregation (Figure 1B). Furthermore, the same construct was used for the stable transformation of Arabidopsis thaliana Col-0 plants. Additionally, in the cells of these transformed plants, AtPII-GFP aggregated in foci in chloroplasts, as observed previously in tobacco cells (Figure 1C), which shows that this phenomenon was not caused by heterologous overexpression. As we observed this focal aggregation of PII proteins regularly, which can be seen in the course of this report, we coined this phenomenon as PII foci.

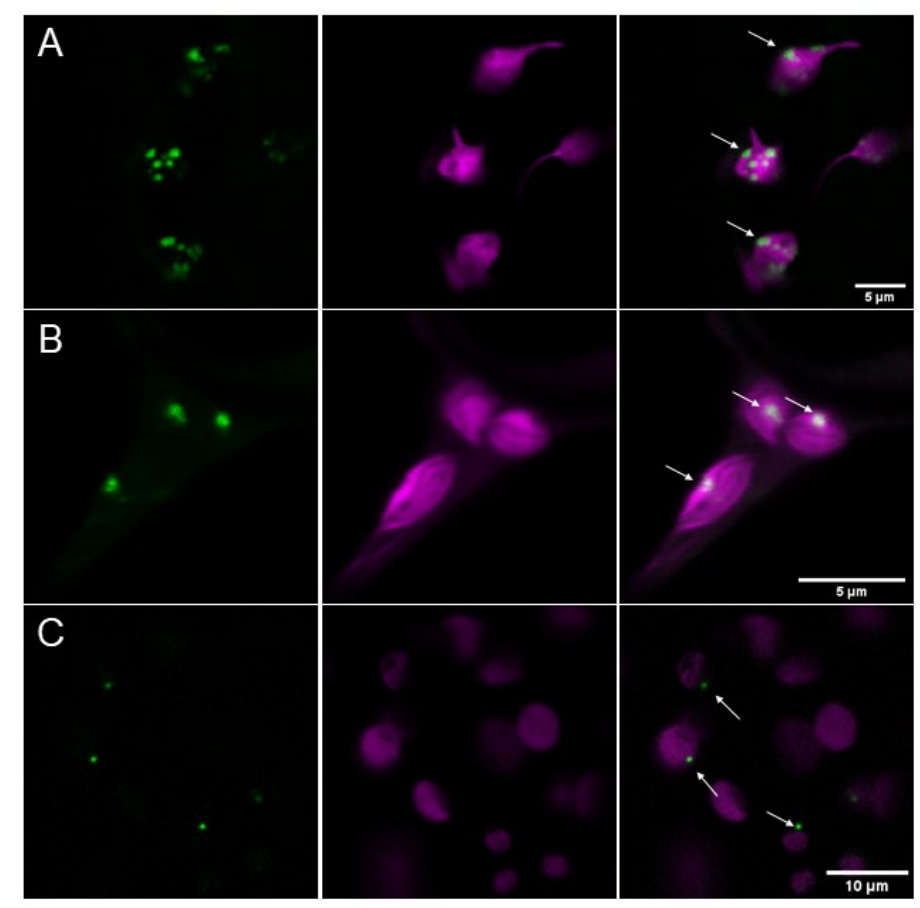

Figure 1. AtPII aggregates in focal structures in chloroplasts. (A) AtPII-GFP (green) under the control of $p 35 S$ ( $p 35 S$ CaMV::AtPII cDNA GFP) and co-expressed with mCherry-tagged transit peptide of tobacco Rubisco (CD3-999 pt-rk [24]; magenta) localizes to plastids in transiently transformed $N$. benthamiana 2 days after infiltration. (B) Genomic AtPII-GFP (green) expressed under the control of the endogenous PII promoter ( $p$ AtPII::AtPII ${ }_{\text {genomic }}-G F P$ ) and co-expressed with mCherry-tagged transit peptide of tobacco Rubisco (CD3-999 pt-rk; magenta) localizes to plastids in transiently transformed N. benthamiana 2 days after infiltration. (C) Genomic AtPII-GFP (green) under the control of endogenous $p A t \mathrm{PII}$ ( $p$ AtPII::AtPII genomic $-G F P$ ) localizes to plastids (magenta) in stably transformed $A$. thaliana. In each row, the GFP fluorescence is shown first, the mCherry fluorescence is shown second, and the merge of both pictures is shown last. White arrows mark exemplarily AtPII aggregates. 
The specific subcellular localization pattern of $A t P I I$ raised the question of whether the formation of PII foci is a general phenomenon or if it is restricted to specific conditions. Therefore, we transformed an AtPII genomic sequence that encoded a C-terminal GFP fusion and was under the control of an ubiquitin promotor ( $p U B Q 10::$ AtPII genomic $-G F P$ ) into Arabidopsis thaliana Col-0 to observe AtPII localization under different conditions. We then tested the impact of different temperature and light regimes on AtPII localization in this line. As can be seen in Figure 2, differences in the formation of PII foci can be observed depending on temperature or changing light quality. In this experiment, most chloroplasts displayed GFP fluorescence throughout the organelle. Nevertheless, PII foci of different sizes formed under all tested conditions to different extents without a clear recognizable trend (Figure 2).
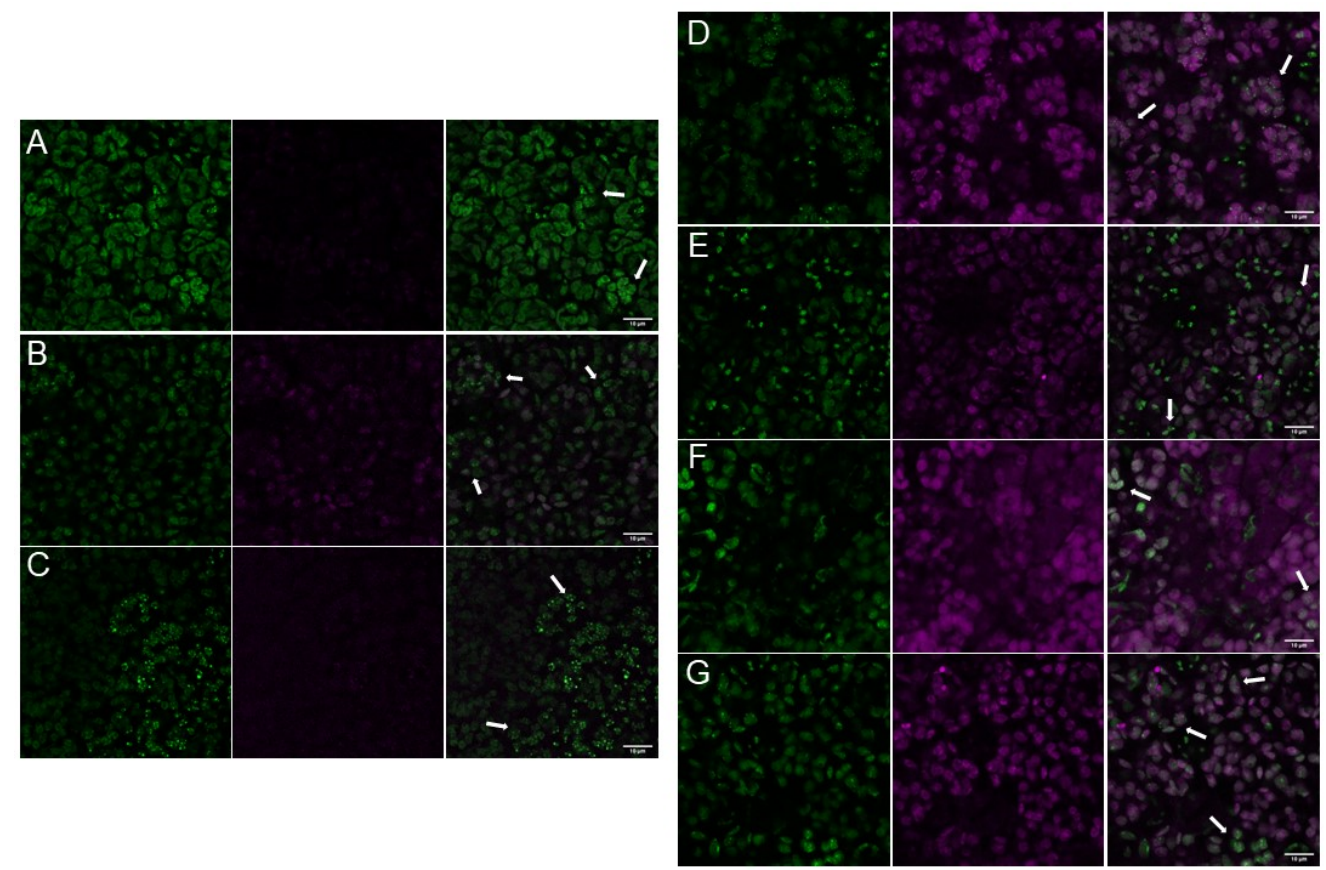

Figure 2. PII foci formation in Arabidopsis thaliana under different temperature and light regimes. Expression of genomic AtPII-GFP under the control of the $p U B Q 10$ promotor $\left(p U B Q 10:: A t \mathrm{PII}_{\mathrm{CDNA}^{-}}\right.$ GFP) was analyzed in 6-day-old seedlings. Seedlings were incubated for $24 \mathrm{~h}$ for temperature treatment in the dark at (A) RT, (B) $8{ }^{\circ} \mathrm{C},(\mathbf{C}) 37^{\circ} \mathrm{C}$, and for light treatment in (D) blue light, (E) green light, (F) red light, and (G) far red light. Seedlings were fixed after incubation. In each row, the GFP fluorescence is shown first, chlorophyll autofluorescence is shown second, and the merge of both pictures is shown last. White arrows: PII foci. Scale bar: $10 \mu \mathrm{m}$.

\subsection{AtPII Interaction with Itself and Other Proteins Takes Place in PII Foci}

Next, we were interested in whether PII foci would also appear when AtPII interacts with itself or with other proteins. Therefore, we applied bimolecular fluorescence complementation (BiFC) to analyze the physical interaction of the candidate proteins. As shown in Figure 3A, co-expression of AtPII fused with nYFP and cYFP in tobacco led to dot-like fluorescence, as observed beforehand. As AtNAGK and AtBCCP1 were previously characterized as PII interactors, we also cloned both coding sequences into the same 2in1 $\mathrm{BiFC}$ vector together with AtPII. Moreover, in these cases, focal aggregation of fluorescence appeared after infiltration (Figure 3B,C). 


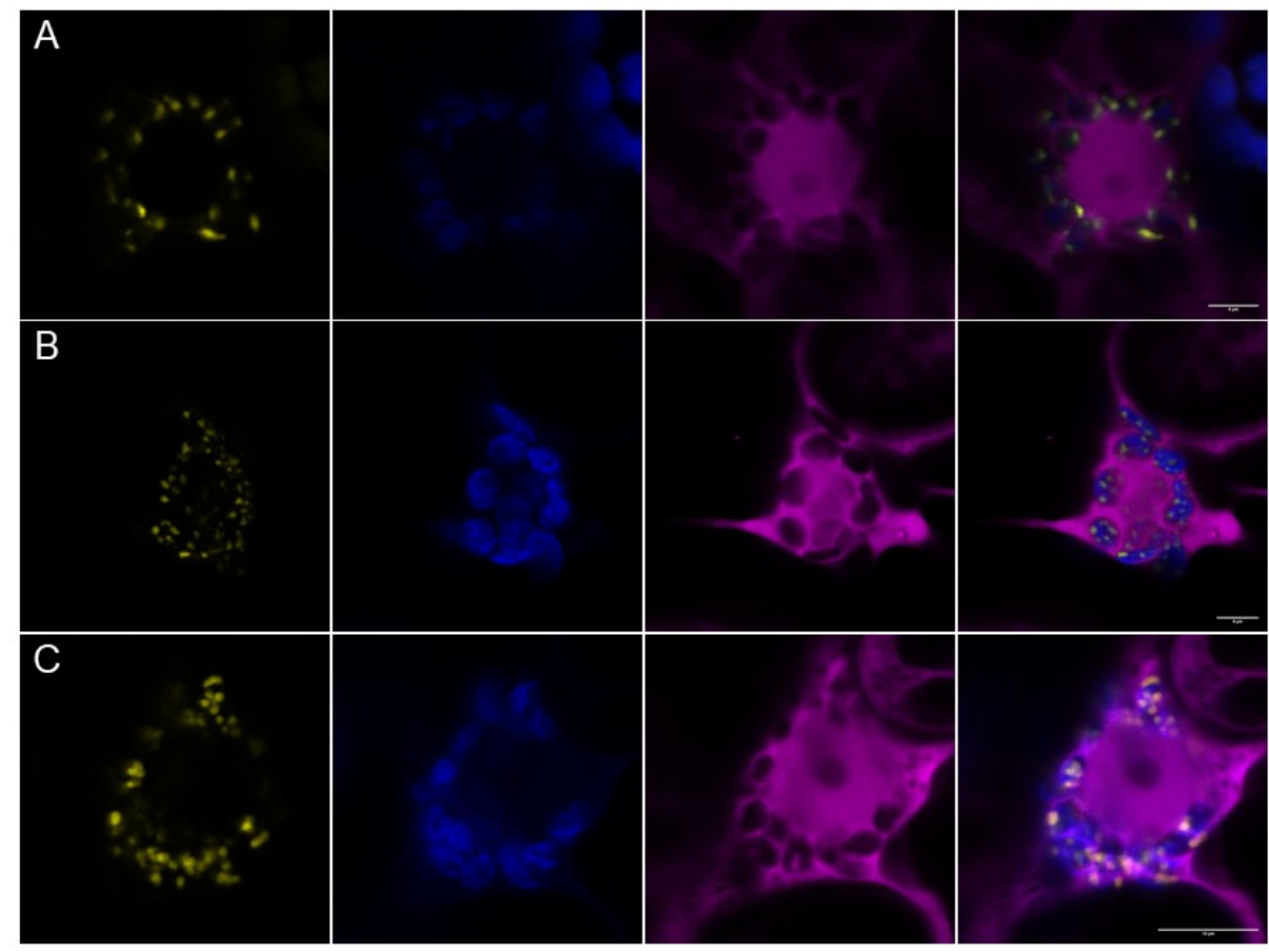

Figure 3. BiFC analysis of AtPII with itself and known interactors in PII foci. AtPII-nYFP was co-expressed with AtPII-cYFP (A), AtNAGK-cYFP (B), and AtBCCP1-cYFP (C), respectively, under the control of $p 35 S$ promotor using $2 \mathrm{in} 1-\mathrm{BiFC}$ vectors. Images were taken 3 days after transient transformation of $N$. benthamiana leaves. In each row, the YFP fluorescence (yellow) is shown first, chlorophyll autofluorescence (blue) is shown second, free RFP fluorescence as expression control (magenta) is shown third, and the merge of all pictures is shown last. Scale bar: $10 \mu \mathrm{m}$.

These observations implied that the interaction of AtPII with itself and other proteins occurs in PII foci. To confirm this finding, we co-expressed AtPII and its putative interacting proteins as C-terminal fusions to GFP and mCherry, respectively, in suitable 2in1 vectors. Then, these vectors were infiltrated into tobacco and FRET/FLIM analyses were applied to co-localizing fluorescent signals. In Figure $4 \mathrm{~A}-\mathrm{C}$, the co-localization of GFP and mCherry signals was observed in all experiments in dot-like structures. Fluorescence lifetime measurements (FLIM) revealed significantly reduced GFP fluorescence lifetime values of the co-localizing signals in comparison to AtPII-GFP alone (Figure 4D). This observation confirms the assumption of physical interaction of AtPII with itself and other proteins in PII foci as such a reduction in fluorescence lifetime only occurs when two fluorescent proteins are at a critical distance of $<10 \mathrm{~nm}$ [25].

Further analysis of AtPII-GFP together with AtNAGK-mCherry additionally revealed that the formation of PII foci evolves within seconds and that they only persist temporarily. In Figure 5, a series of images of such an interaction over a time range of more than $2 \mathrm{~min}$ is shown. As can be seen in this figure, some of the PII foci evolved and vanished within a minute whereas others were visible over the whole range of time. Further analyses of PII foci showed that some of them were even stable for more than half an hour (Figure S1).

\subsection{Characterization of PII Foci Points to Plastidic Protein Degradation}

Detecting AtPII in focal aggregates in plastids opened the question of whether these suborganellar structures have been characterized before. As one candidate structure in plastids, we tested whether PII foci are part of nucleoids. Therefore, DNA in the chloroplasts was visualized with $\mathrm{YO}-\mathrm{PRO}^{\mathrm{TM}}$ iodide, as previously described [26]. In all the tobacco cells expressing AtPII-RFP, this fluorescent signal could be clearly distinguished from that 
of YO-PRO1 ${ }^{\mathrm{TM}}$ iodide (Figure S2), which indicates that PII foci are not part of the nucleoids in plastids.

Subplastidial compartments, similar to PII foci, have also been reported to represent vesicle-like structures for protein degradation from chloroplasts $[27,28]$. The small subunit of Rubisco (RBCS) is known to be part of such plastidial protein degradation vesicles, known as the Rubisco containing bodies (RCBs) $[27,29,30]$.
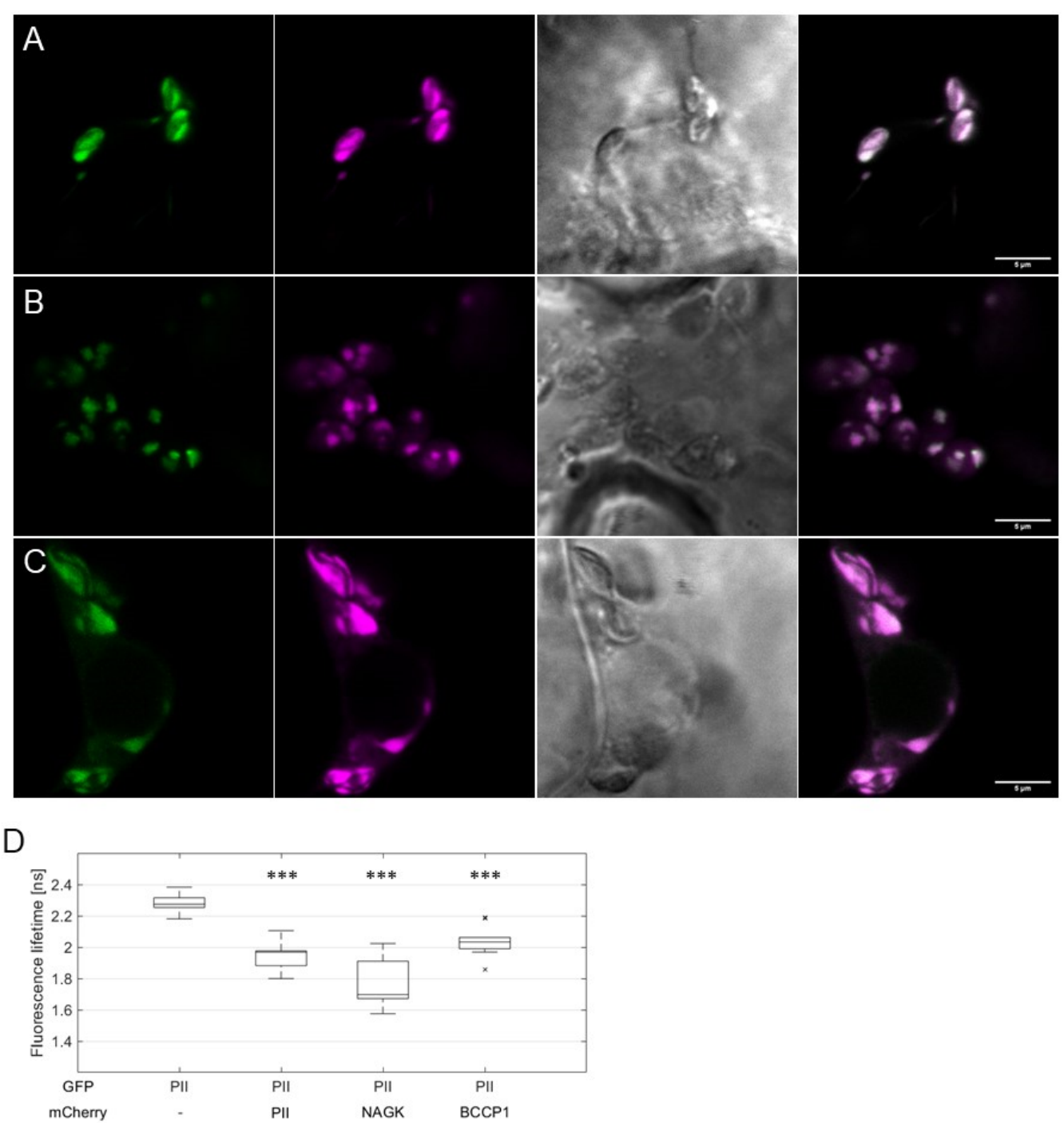

Figure 4. FRET/FLIM analysis of AtPII interaction with candidate proteins in PII foci. AtPII-GFP was co-expressed with AtPII-mCherry (A), AtNAGK-mCherry (B), and AtBCCP1-mCherry (C), respectively, under the control of $p 35 S$ promotor in $N$. benthamiana using 2 in 1 FRET vectors. Images were taken 2 days after transient transformation of $N$. benthamiana. In each row, the fluorescence of GFP is shown first, mCherry (magenta) is shown second, the brightfield image is shown third, and the merge of both fluorescence pictures is shown is shown last. Scale bar: $10 \mu \mathrm{m}$. (D) FLIM analyses of fluorescent co-localising signals in (A-C). Student's t-test used for calculation of significance. Data points marked with an " $x$ " represent statistical outliers of measurement. ${ }^{* * *} p<0.001$. 


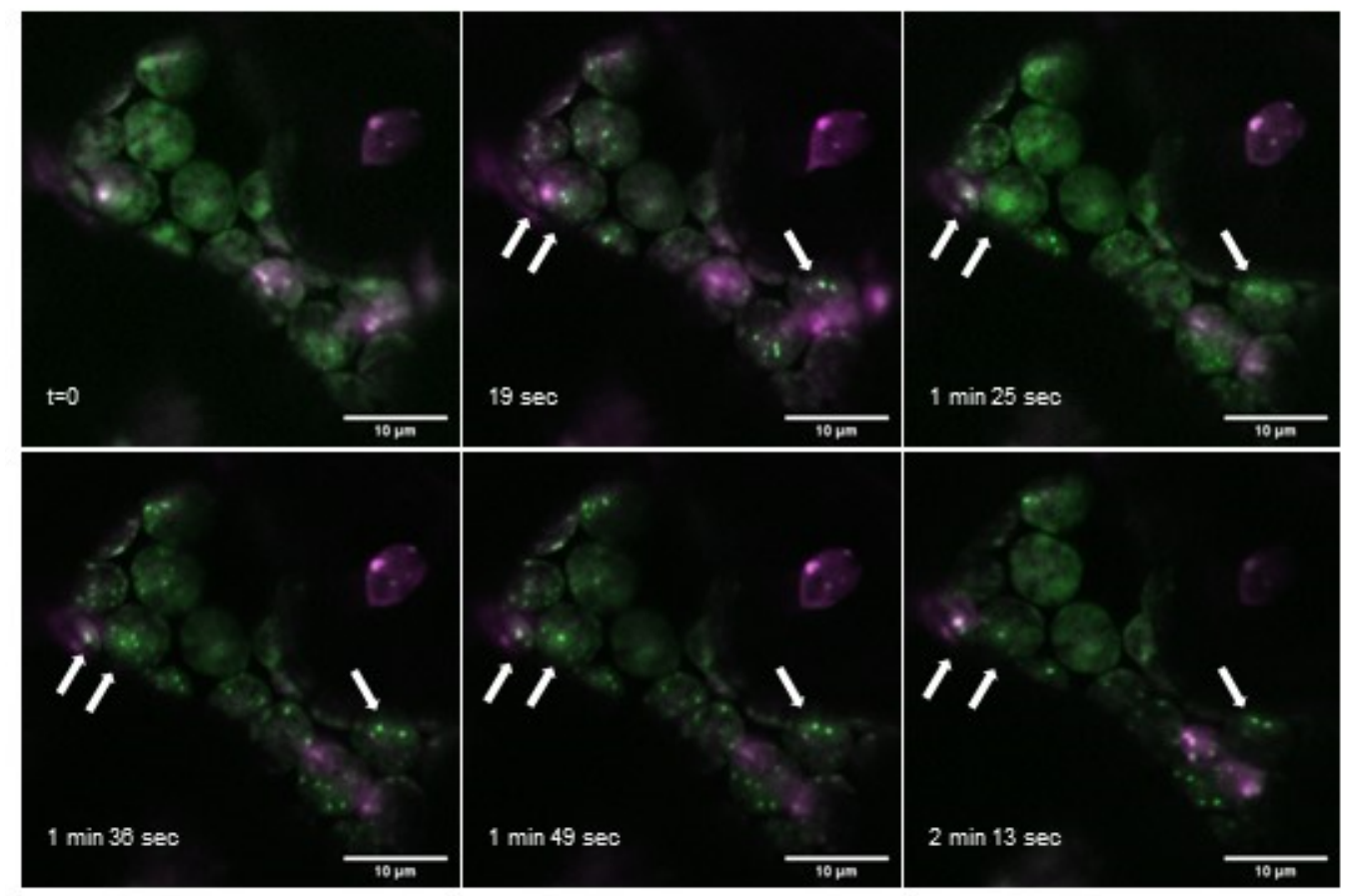

Figure 5. Appearance of PII foci over time. Overlay images of time series of AtPII-GFP (green) and AtNAGK-mCherry (magenta), both expressed under the control of $p 35 S, 2$ days after transient transformation of $N$. benthamiana. White arrows mark exemplarily PII foci observable over the whole time range. Scale bar: $10 \mu \mathrm{m}$.

To test whether PII foci are part of the plastidic protein degradation apparatus, we coexpressed AtPII-GFP with AtRBCS3B-RFP in tobacco cells. Co-localization of the fluorescent signals in chloroplasts (Figure 6A), as well as the decreased GFP lifetime in FLIM analyses (Figure 6D), confirmed our assumption. Furthermore, some of the co-localizing fluorescent foci could be found outside the chloroplasts (Figure 6A), supporting the assumption that AtPII is part of plastidial protein degradation vesicles. To support this hypothesis, we also tested other proteins involved in autophagy-dependent protein degradation of RCBs [27,31]. For this purpose, TagRFP or RFP-tagged AtNBR1, Atg8e, and Atg8g from A. thaliana were co-expressed with AtPII-GFP [32]. In particular cases, the co-localization of GFP and RFP signals was also observed (Figure S3a-c).

The co-localization of $A t P I I$ with proteins mediating different protein degradation pathways led to the assumption that AtPII may even be involved in the earlier steps of this process, such as protein quality control (PQC). Previously, it was shown that two enzymes of the methylerythritol-4-phosphate (MEP) pathway, deoxyxylulose-5-phosphate synthase (DXS) and reductoisomerase (DXR), undergo such PQC in Arabidopsis chloroplasts by aggregation, similar to PII foci $[33,34]$. To test whether AtPII is also involved in PQC, such as $A t \mathrm{DXR}$ and $A t \mathrm{DXS}$, they were also cloned into suitable 2in1 vectors together with AtPII for fluorescence microscopy and subsequent FRET/FLIM analyses in tobacco after infiltration. The microscopic images revealed partial co-localization of AtDXR and AtDXS with PII foci (Figure 6B,C). Additionally, in FRET/FLIM analyses of co-localizing fluorescent signals a significant decrease in fluorescent lifetime was detected, indicating in vivo physical interaction of $A t \mathrm{PII}$ with both $A t \mathrm{DXR}$ and $A t \mathrm{DXS}$ (Figure 6D). 


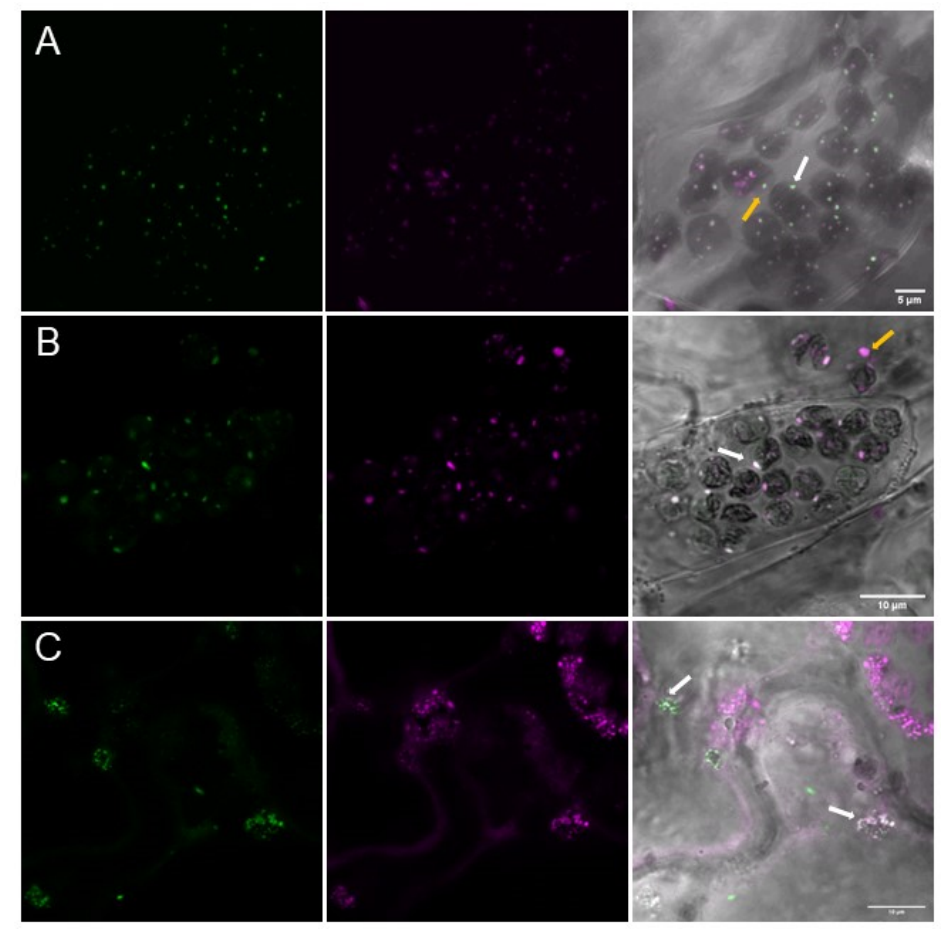

D

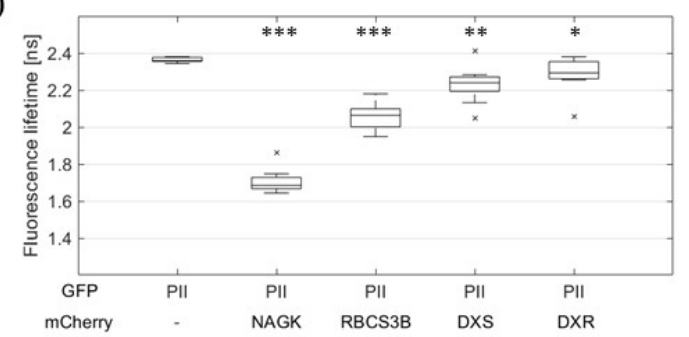

Figure 6. AtPII is found in different plastidial aggregates. AtPII-GFP was co-expressed with AtRBCS3B-mCherry (A), AtDXR-mCherry (B), and AtDXS-mCherry (C), respectively, under the control of $p 35 S$ in $N$. benthamiana. In each row, the GFP fluorescence is shown first, the mCherry fluorescence is shown second, and the merge of both fluorescence images with the brightfield image as background is shown last. White arrows mark exemplarily AtPII aggregates in chloroplasts (dark and round structures in the brightfield image), orange arrows indicate extraplastidic vesicle-like structures. (D) FLIM analyses of fluorescent co-localizing signals in (A-C) together with AtPIIGFP/AtNAGK-mCherry as positive control. Student's $t$-test used for calculation of significance. Data points marked with an " $x$ " represent statistical outliers of measurement. ${ }^{*} p<0.05$; ${ }^{* *} p<0.01$; *** $p<0.001$.

\subsection{The C-Terminus of AtPII Is Responsible for the Formation of PII Foci}

The observation that PII is found in plastidic protein degradation aggregates opened the question of whether this protein is only found there due to co-degradation in PQC, or whether PII is indeed mediating the aggregation with other proteins. Furthermore, we wondered about the differing sizes of the PII foci that we observed in our microscopic studies. We assumed that a targeted change in PII protein structure could lead to differences in PII foci formation. To test this hypothesis, we created a C-terminally truncated version of AtPII without the so-called Q-loop. Almost all plant PII proteins possess a Q-loop motif at their C-terminus, which is responsible for glutamine binding. The Q-loop affects the conformation of the T-loop in plant PII proteins, which is responsible for interaction with target proteins [13]. 
Therefore, an additional version of AtPII-GFP without the Q-loop was cloned, in which the last 15 amino acids $\left(A t \mathrm{PII}_{\triangle C T 15}-G F P\right)$ were deleted. For further analyses we co-expressed AtPII-GFP or AtPII $\Delta \mathrm{CT}_{15}$-GFP with AtPII-mCherry, AtNAGK-mCherry, and AtRBCS3B-mCherry into tobacco leaves. To test the physical interaction of AtPII-GFP and AtPII ${ }_{\triangle \mathrm{CT} 15}$-GFP with the mCherry-tagged interactors, the GFP-tagged proteins were first isolated from protein extracts using GFP traps. Afterwards, the co-eluted proteins were detected by Western blot analysis with an $\alpha$ RFP antibody. As shown in Figure S4, infiltration of either AtPII-GFP or $A t \mathrm{PII}_{\Delta \mathrm{CT} 15}$-GFP led to the co-purification of all co-infiltrated interactors. These results indicate that $A_{t P I I}{ }_{\Delta \mathrm{CT} 15}-\mathrm{GFP}$ is still able to interact with itself and its binding partners.

In contrast, fluorescent microscopic analyses of these co-infiltrations revealed differences between the AtPII variants in terms of PII foci formation. Co-infiltrated with AtPII-GFP, the number of PII foci was higher and their size smaller in comparison to AtPII ${ }_{\Delta \mathrm{CT} 15}-\mathrm{GFP}$ (Figure 7A-F). Additionally, with $A t \mathrm{PII}_{\Delta \mathrm{CT} 15}-\mathrm{GFP}$, the GFP signals were not confined to PII foci, but tended to spread within the whole chloroplast (Figure 7D-F).

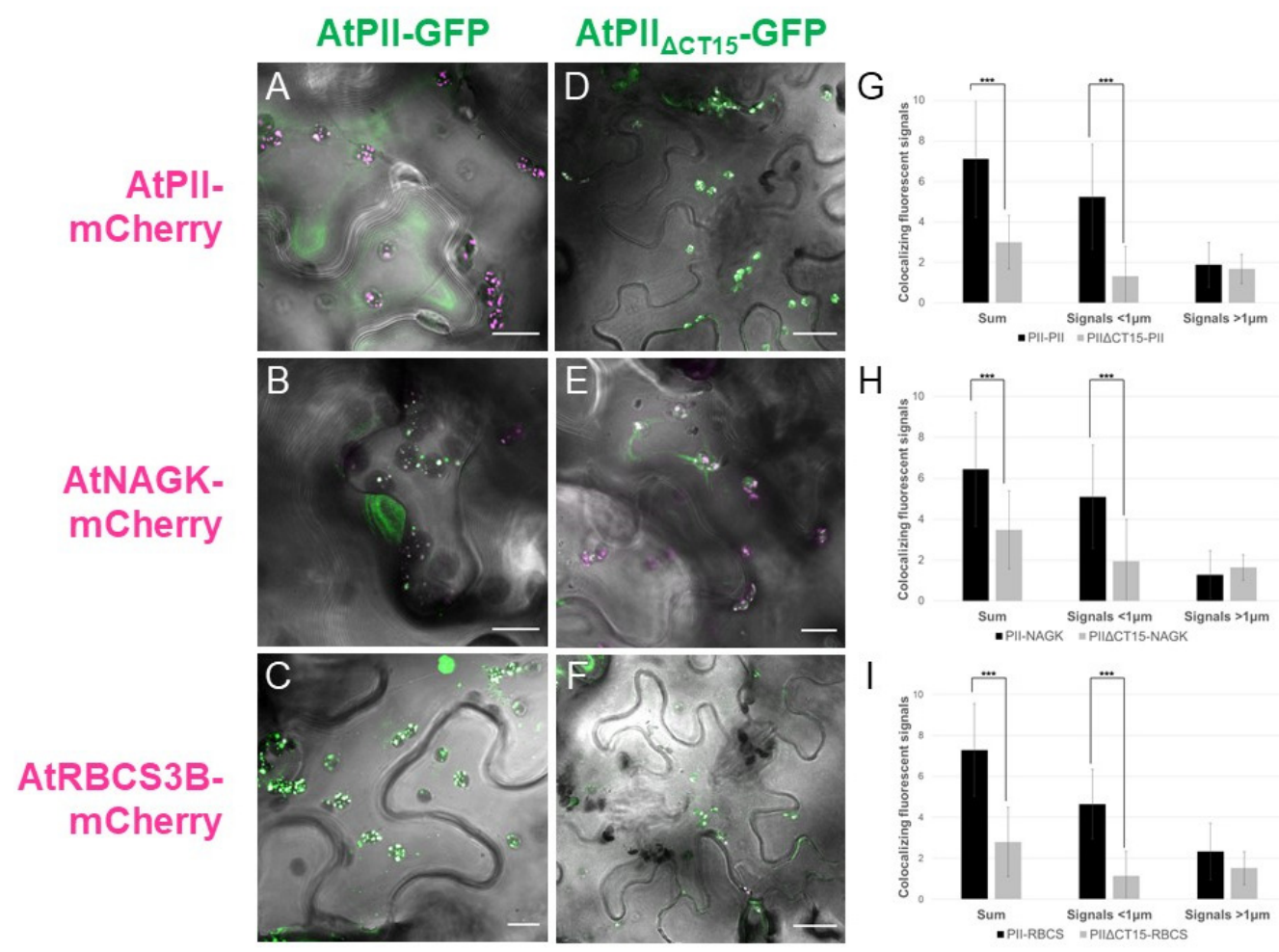

Figure 7. Truncation of the C-terminus of AtPII leads to different aggregation behavior. AtPII-GFP or AtPII $\Delta \mathrm{CT} 15-\mathrm{GFP}$ were co-expressed either with AtPII-mCherry ((A,D), respectively), AtNAGKmCherry ((B,E), respectively) or AtRBCS3B- mCherry ( $\mathbf{C}, \mathbf{F})$, respectively), under the control of p35S in N. benthamiana. Each of these pictures shows the merge of GFP and mCherry fluorescence with the brightfield image as background. Size bars show $10 \mu \mathrm{m}$ except for (D) and (F) where they indicate $22 \mu \mathrm{m}$. In G-I, the average total number (Sum) and the number of small and large co-localizing fluorescent signals per chloroplast for the co-expressions of AtPII-GFP / AtPII $\Delta \mathrm{CT} 15-\mathrm{GFP}+$ AtPIImCherry $(\mathbf{G}),+$ AtNAGK-mCherry $(\mathbf{H})$, and AtRBCS3B-mCherry $(\mathbf{I})$ are provided $(n=25)$. Student's $t$-test used for calculation of significance. ${ }^{* * *} p<0.001$.

This observation was supported by quantitative analysis of these images. Therefore, we differentiated and counted the co-localizing fluorescence signals according to their size in signals smaller than $1 \mu \mathrm{m}$ and those larger. In Figure $7 \mathrm{G}-\mathrm{I}$, the number of colocalizing fluorescence signals per plastid is provided. It is obvious that the truncation of the C-terminus of AtPII leads to a significant reduction in PII foci number in all tested cases. Specifically, the number of small signals decreased significantly in chloroplasts 
expressing AtPII $_{\Delta \mathrm{CT} 15}$-GFP, whereas the number of large signals did not differ significantly (Figure 7G-I).

\section{Discussion}

In the present study it was shown that AtPII, either alone or co-expressed with its interaction partners, was almost exclusively found in aggregates in the chloroplasts. This aggregation, coined as PII foci in this study, took place irrespective of the promotor driving AtPII expression or the plant species (Arabidopsis or Nicotiana) it was expressed in (Figures 1 and 2). This impression was supported by the microscopic images of BiFC experiments of AtPII interaction with itself, where the fluorescent signals were almost strictly confined to foci (Figure $3 \mathrm{~A}$ ).

As the physiological function of the PII protein in plants is still not clearly resolved, the appearance of such a characteristic structure as the PII foci raised several questions. PII proteins were characterized in plants for the first time more than 20 years ago [7]. An obvious question regarding PII foci is whether this phenomenon was observed before that time. Revisiting former localization studies of plant PII proteins revealed that the aggregation of this protein in plastids had indeed been observed before but did not attract further interest. In Arabidopsis cells, PII was detected for the first time in chloroplasts by immunolocalization in a dotted pattern [35]. GFP fusions of two PII isoforms from maritime pine (Pinus pinaster) expressed in tobacco cells also revealed a similar localization pattern [36]. Focal aggregation of PII has even been observed in evolutionary distant organisms such as the cyanobacterium Synechococcus elongatus [37]. These reports indicate that the formation of PII foci is an evolutionary conserved phenomenon and is not limited to AtPII due to the slightly aberrant structure of the C-terminus without the glutamine binding site [13].

The presented results from our FRET/FLIM analyses, BiFC, and co-immunoprecipitation experiments strongly support the direct interaction between AtPII and the tested proteins within PII foci. However, final evidence for the physical interaction of AtPII has only been provided for AtNAGK $[9,38]$, whereas physical binding analyses with methods such as surface plasmon resonance (SPR), isothermal calorimetry (ITC), or microscale thermophoresis (MST) for all other binding partners are still lacking. However, the type of interaction may still be indirect, as it has been shown for bacterial PII-PipX complexes to interact with the transcription factor PlmA [39], although a PipX-like protein has not been shown in plants to date. Nevertheless, the results of our studies revealed the close proximity (approximately $<10 \mathrm{~nm}$ ) between AtPII and the tested proteins. These findings make a regulatory influence of AtPII on neighboring proteins very likely. These proteins in close proximity of AtPII and their functions will be the next target of future studies.

Our experiments with $A t \mathrm{PII}_{\Delta \mathrm{CT} 15}$-GFP trap analysis indicated that the C-terminal Q-loop does not seem to be essential for the binding of PII to its interactors, although it has been suggested that this region stabilizes the T-loop of AtPII and thereby the binding to AtNAGK [13]. This contradiction could be explained by the different sensitivity range of the analytics, where biophysical methods such as SPR fail to detect weaker interactions [40]. The fact that the formation of PII foci requires the Q-loop indicates that PII-target complex formation may not be the driving force in foci formation, but rather indicates a regulatory role of the C-terminus of AtPII in the formation of PII foci. This region was shown to be responsible for glutamine binding of plant PII protein with an evolutionary peculiar exception of its homologs in Brassicaceae [13]. In this regard, it would be highly interesting to repeat these experiments with PII homologs from other plants, especially with C-terminally truncated versions, to investigate whether there is a general correlation between glutamine, nitrogen supply, and the formation of PII foci. In addition, the aggregation and disintegration dynamics of PII foci ( Figures 5 and S1) in response to light, temperature, and nutrient supply should be analyzed in more detail; this may provide further valuable information about the role of PII proteins in these processes. 
The observation of PII foci leads to the greater question of whether this structural feature can be related to a physiological function. As described in Section 2.3, one putative function of PII in plants may be its contribution to plastidic protein degradation. This was deduced due to its subcellular co-localization and interaction with different components of the plastidic protein degradation pathways (Figure S3) and the observation of PII foci outside of chloroplasts (Figure 6A,B). Further analyses indicated the physical interaction of AtPII in PII foci with AtDXR and AtDXS, which are known to aggregate during inactivation and degradation $[33,34]$. The accumulation and aggregation of both proteins is initiated and regulated by the so-called chloroplast unfolded protein response (cpUPR). In this process, different Clp proteases and heat shock proteins (HSPs) are employed to regulate the levels of proteins, such as AtDXR and AtDXS [34]. Furthermore, pharmacological and genetic approaches have revealed a crucial role of plastome gene expression (PGE) in cPUPR [34]. Our results of AtPII interacting with AtDXR and AtDXS in PII foci imply the involvement of PII in cPUPR. This assumption is supported by the experiments with the C-terminally truncated $A t \mathrm{PII}$ variant $A t \mathrm{PII}_{\Delta \mathrm{CT} 15}-\mathrm{GFP}$. Infiltration of this construct together with AtPII-, AtNAGK-, or AtRBCS3B-mCherry, led to the diffusion of PII foci (Figure 7. This is reminiscent of images of AtDXS-GFP expressing Arabidopsis plants either treated with an inhibitor of PGE or mutated in plastidic ribosome formation. In both cases, the dotted aggregation pattern of AtDXS-GFP was dispersed [34]. A putative function of PII in cpUPR would explain why, so far, the role of this protein in plants remains largely cryptic. Several different anabolic pathways such as the synthesis of tetrapyrrole, chlorophyll, carotenoids, and isoprenoids, have been identified as prone to regulation of protein aggregation and degradation by cpUPR (for a summary, see [41]). These pathways were not the focus of the investigation of PII-regulated processes, yet they should be investigated in the future.

It is noteworthy that in this study several novel interactors of a PII protein from plants were reported. In addition to well characterized interactors such as AtNAGK, AtBCCP1 and -2 , and $A t B A D C 1-3$ [12], the number of proteins and their functional range seem to be growing. This resembles the situation found for bacterial PII homologs and their interaction partners: for the PII homolog GlnZ from Azospirillum brasilense, 37 interaction partners could be identified in ligand fishing assays [4]. In the cyanobacterium Synechocystis sp., all major transporter proteins involved in ammonium, nitrate, and urea transport interact with the bacterial PII homolog GlnB [42]. Most interestingly, only NAGK could be identified as a common interactor in both studies, whereas all other proteins were functionally different [4]. Therefore, it seems reasonable that the list of this network in bacteria cannot be closed soon. With the novel Arabidopsis PII interactors reported here, it can be concluded that PII interaction networks with many diverse protein partners are also an evolutionary conserved property in higher plants. However, these novel interactors escaped identification by co-purification experiments due to moderate affinities [12], and therefore should be analyzed in more detail.

Nevertheless, even the characterized PII network in plants implies multiple regulatory functions of plant PII proteins. Interestingly, localization studies of AtNAGK alone also revealed a dotted distribution in Arabidopsis chloroplasts such as PII foci [43]. The same was observed for AtBADC1, a protein that facilitates the physical interaction of the PII interactor AtBCCP1 within htACCase [44]. It was further mentioned in this report that several other proteins from Physcomitrella and potato involved in lipid metabolism were also observed in foci in chloroplasts $[45,46]$. Furthermore, colleagues noticed a similar subcellular distribution of PII proteins [44]. In this regard, plastidic enzymes of lipid metabolism may be additional candidates of the PII foci network, which needs to be confirmed in future.

Regardless of the physiological functions of PII foci, the question remains as to whether PII is central to these suborganellar structures. Therefore, many of the presented subcellular localization studies have to be repeated in Arabidopsis in an AtPII null background such as PIIS2, an AtPII knock-out line that had been isolated and previously described [19]. In the present study, most of the results with AtPII were achieved in a heterologous 
system (N. benthamiana) with an endogenous PII encoding gene, whose impact on different regulatory phenomena must not be neglected as it can be performed in a null background system. It would be highly interesting to express proteins such as NAGK or BCCP from Arabidopsis alone and in conjunction with AtPII in an AtPII knock-out line to determine whether the focal aggregation of PII interactors is directly dependent on PII in plants.

Altogether, it can be stated that the presented results unraveled novel interactors of AtPII proteins, which led to novel physiological processes regulated by PII proteins in plants. Although the regulatory mechanism is still unclear, the aggregation of AtPII together with its interactors point to different possibilities of regulatory functions; the regulatory role of PII in plastidic protein degradation has to be considered as one possibility. However, the presented data regarding aggregation dynamics and the proportion of extraplastidic PII foci make an exclusive role in this respect less probable. Another possibility to be tested in this regard should be the role of plant PII proteins in the formation of multi-enzyme assemblies or metabolons, which are known to be central to substrate channeling and metabolic regulation in plants too (for a summary, see [47]). As PII proteins bind to a variety of metabolic enzymes, as mentioned above, the involvement of PII as a scaffolding protein is possible. Nevertheless, finding answers to these questions will be one of the central tasks for the elucidation of the physiological functions of PII proteins in plants.

\section{Materials and Methods}

\subsection{Plant Material and Growth Conditions}

For transformation of Arabidopsis thaliana (Col-0), plants were grown on T- and R-soil mixed with sand (10:10:1) under long day conditions $\left(16 \mathrm{~h}\right.$ light at $18{ }^{\circ} \mathrm{C}, 8 \mathrm{~h}$ dark at $\left.15{ }^{\circ} \mathrm{C}\right)$ at a humidity of $55-60 \%$ in a greenhouse. Stable transformed lines were generated using the floral dipping method according to [48].

Syringe-mediated infiltration $[49,50]$ was used for transient transformation of leaves of three- to four-week-old $N$. benthamiana with A. tumefaciens carrying plasmids of interest. Growth of $A$. tumefaciens and infiltration was performed according to protocol described in [51] derived from protocols of $[49,50,52,53]$ with the modification that cells were not washed with sterile $\mathrm{H}_{2} \mathrm{O}$ before resuspension in AS medium.

For specific light and temperature treatment of Arabidopsis, plants seeds were sown on 1/2 MS media (Murashige and Skoog basal salt, DUCHEFA Biochemie B. V. (Haarlem, Netherlands)). After stratification for one night at $4{ }^{\circ} \mathrm{C}$, plates were transferred for one day to constant light at $23^{\circ} \mathrm{C}$ and placed in black boxes for additional three days under constant light at $22{ }^{\circ} \mathrm{C}$. One plate per condition was placed for $24 \mathrm{~h}$ for temperature treatments in dark at $8{ }^{\circ} \mathrm{C}, 23^{\circ} \mathrm{C}$, and $37^{\circ} \mathrm{C}$, and for light treatments in blue light (BL), green light (GL), red light (RL), and far-red light (FRL). For further microscopic analysis, harvested seedlings were pre-fixed in $2 \times$ SSC $+4 \%$ formaldehyde for $4 \mathrm{~h}$, followed by vacuum infiltration three times for $15 \mathrm{sec}$, and an additional incubation step for $30 \mathrm{~min}$. Seedlings were transferred to 6 -well plates and washed once in $2 \times$ SSC overnight and twice for $1 \mathrm{~h}$. Seedlings were mounted on $\mathrm{dH}_{2} \mathrm{O}$ on microscope slides and covered with cover glasses. Microscopic analysis was performed with Zeiss LSM880. Growth conditions and light treatment were modified according to protocol by [54].

\subsection{Generation of Plant Expression Vectors}

Coding DNA sequences (CDS) of AtPII (AtGLB1-Start; AtGLB1-End), AtPII ${ }_{\Delta C T 15}$ (AtGLB1-Start; AtPII-C2A), AtNAGK (NK_AtNAGKstart; NK_AtNAGKend), AtBCCP1 (NK_AtBCCP1start-2; NK-BCCP1end), and AtRBCS3B (NK_RGCS1A-FP; NK_RGCS1A$\mathrm{RP}$ ) were amplified from cDNA of Arabidopsis thaliana Col-0 seedlings (for primer sequences, see Table S1) for cloning into pENTR ${ }^{\mathrm{TM}} / \mathrm{D}-\mathrm{TOPO}^{\circledR}{ }^{\circledR}\left(\mathrm{pENTR}^{\mathrm{TM}}\right.$ Directional TOPO ${ }^{\circledR}$ Cloning $^{\circledR}$ Kits from Invitrogen (Carlsbad, CA, USA)) followed by LR (LR clonase, Invitrogen (Carlsbad, CA, USA)) into either pUBQ10-Dest [55], pH7FWG2,0-Dest, or pB7RWG2,0Dest ([56]; for specifications of vectors see Table S2). 
Genomic constructs of the endogenous AtPII promoter ( $-269 \mathrm{bp})$, together with the genomic coding sequence of $A t \mathrm{PII}$ or the genomic coding AtPII sequence only, were amplified using NK_proAtPIIstart/AtGLB1-End or AtGLB1-Start/AtGLB1-End, respectively, on genomic DNA extracted from Arabidopsis thaliana Col-0, followed by cloning into $\mathrm{pENTR}^{\mathrm{TM}} / \mathrm{D}-\mathrm{TOPO}^{\circledR \circledR}{ }^{\circledR}$. These entry constructs were cloned into pMDC107 [57] or pUBQ10-Dest [55], respectively, by LR clonase reaction.

For the generation of 2in1 constructs for BiFC and FLIM analysis, CDS of genes harbouring either $\mathrm{P} 3 \mathrm{P} 2$ or $\mathrm{P} 1 \mathrm{P} 4$ attachment sites were amplified, followed by BP reaction (BP clonase, Invitrogen (Carlsbad, CA, USA)) into pDONR221-P3P2 and pDONR221P1P4 (Invitrogen (Carlsbad, CA, USA)), respectively, and LR reaction into pBiFCt-2in1$\mathrm{CC}$ and pFRETgc-2in1-CC. The following primer combinations were used (for primer sequences, see Table S1): AtPII P2P3 (NK_attP2P3-PIIstart; NK_attP2P3-PIIend), AtPII P1P4 (NK_attP1P4-PIIstart; NK_attP1P4-PIIend), AtNAGK P1P4 (NK_attP1P4-NAGKstart; NK_attP1P4-NAGKend), AtBCCP1 P1P4 (NK_attP1P4-BCCP1start; NK_attP1P4-BCCP1end), AtRBCS3B (NK_RGCS1A-P1P4-FP; NK_RGCS1A-P1P4-RP), AtDXS (NK_attP1-FP-DXS; NK_attP4-RP-DXS), and AtDXR (NK_attP1-FP-DXR;NK_attP4-RP-DXR).pENTR-L1-GentRL4 was used for the generation of the donor-only controls for BiFC and FLIM analysis by multisite LR in pBiFCt-2in1-CC and pFRETgc-2in1-CC together with pENTR-L3L2-PIIend.

\subsection{Microscopic Analyses}

Fluorophores were imaged using a Leica TCS SP8 AOBS FLIM and Zeiss LSM880 Airyscan with a 63X/NA1.2 water objective. GFP and YO-PRO ${ }^{\mathrm{TM}}-1$ iodide were excited at $488 \mathrm{~nm}$ and YFP at $514 \mathrm{~nm}$ using an Argon laser. RFP, mCherry, and chlorophyll were excited at $561 \mathrm{~nm}$ using a DPSS $561 \mathrm{~nm}$ laser.

YO-PRO ${ }^{\mathrm{TM}}$-1 iodide (Thermo Fisher Scientific (Waltham, MA, USA)) staining was modified from [26]. N. benthamiana leaves were transiently transformed with A. tumefaciens harboring AtPII-RFP under the control of $p 35 S$, together with A. tumefaciens harboring P19 or A. tumefaciens harboring P19 alone. Leaf disks were cut out three days after infiltration, incubated in $2 \times \mathrm{SSC}(0.3 \mathrm{M} \mathrm{NaCl}, 30 \mathrm{mM}$ sodium citrate, $\mathrm{pH} 7.0)+/-\mathrm{RNase} \mathrm{A}$ $(10 \mu \mathrm{g} / \mathrm{mL})$, or $2 \times \mathrm{SSC}+1 \times$ DNase I buffer + DNase I $(100 \mathrm{U} / \mathrm{mL})$ for $4 \mathrm{~h}$ at $37^{\circ} \mathrm{C}$, and transferred to $2 \times \mathrm{SSC}+4 \%$ formaldehyde. Leaf disks were vacuum infiltrated for $15 \mathrm{sec}$ at $300 \mathrm{mbar}$ three times, followed by incubation for $15 \mathrm{~min}$. Washing was performed three times in $2 \times$ SSC. Leaf disks were stained with DAPI $(1 \mu \mathrm{g} / \mathrm{mL})+\mathrm{YO}^{\mathrm{PRO}}{ }^{\mathrm{TM}}-1$ iodide $(5 \mu \mathrm{g} / \mathrm{mL})$ in $2 \times$ SSC overnight and washed $1 \times$ with $1 \times$ SSC. Leaf disks were mounted on microscopic slides on SSC/glycerol (50\% $2 \times$ SSC $+50 \%$ glycerol) and covered with cover slips. Confocal imaging was performed using a Zeiss LSM880 Airyscan.

BiFC analyses were performed according to a modified protocol of [58] three days after transient transformation of Nicotiana benthamiana leaves with Agrobacterium tumefaciens harboring 2in $1 p B i F C$ vectors of interest. Internal RFP fluorescence was used as the transformation control.

FRET-FLIM measurements were performed with Leica TCS SP8 AOBS FLIM equipped with SymPhoTime software (PicoQuant GmbH (Berlin, Germany)), with PicoHarp 300 (PicoQuant GmbH (Berlin, Germany)) for FLIM measurements and TimeHarp 260 Nano (PicoQuant GmbH (Berlin, Germany)) for rapidFLIM measurements. Measurements were taken of transiently transformed leaf disks of $N$. benthamiana leaves with A. tumefaciens GV3101 carrying 2in1 pFRET vectors of interest. FLIM measurements were performed according to [59] and [51]. Two biological replicates (FLIM and rapidFLIM) were measured in five to six regions (FLIM) and four to five regions (rapidFLIM) containing plastids in the epidermis. For FLIM measurements, acquisition was performed until 700 photons in the brightest point were counted. For rapidFLIM measurements, acquisition was performed until 1500 photons at the brightest point were counted.

All images acquired were processed using Fiji (Fiji is the same as Imagej; [60] was based on ImageJ) and Microsoft Office 2019 PowerPoint (Microsoft Corporation (Redmond, Washington, DC, USA). 


\subsection{Statistical Analyses}

Statistical analyses of FLIM measurements using two-sided Student's $t$-test as well as a generation of box plots were carried out in Matlab (The MathWorks Inc. (Natick, MA, USA)). Statistical analyses of PII foci numbers were performed using two-sided Student's $t$-test in Microsoft Excel.

Supplementary Materials: The following are available online at https:/ /www.mdpi.com/article/ $10.3390 /$ ijms222312666/s1.

Author Contributions: Conceptualization, K.F. and Ü.K.; investigation, N.K. and K.-F.P.; writingoriginal draft preparation, N.K., K.F. and Ü.K.; supervision, K.F. and Ü.K.; funding acquisition, K.F. All authors have read and agreed to the published version of the manuscript.

Funding: This work was funded by a grant of the Deutsche Forschungsgemeinschaft (DFG; Fo195/13-1). Additionally, it was supported by a PhD scholarship to N.K. according to the Landesgraduiertenförderungsgesetz from the Ministry of Science, Research and the Arts by the State of BadenWürttemberg in the promotion association 'Of Plants and Men'. Scientific equipment was supported by the DFG with a grant for scientific equipment (INST 37/819-1 FUGG, INST 37/965-1 FUGG). We acknowledge support by Open Access Publishing Fund of University of Tübingen.

Acknowledgments: Many thanks for the help of Xuan Tran Vi Le and the MathWorks forum on writing the script for box plot generation. pB7FWG2,0-DXS and pB7FWG2,0-DXR were kindly provided by Manuel Rodriguez-Concepcion. Vectors for the transient expression of TagRFP-Atg8e, TagRFP-Atg8g, and AtNBR1-RFP were kindly provided by Suayib Üstün. We are also grateful to him for critically reading the manuscript.

Conflicts of Interest: The authors declare no conflict of interest.

\section{References}

1. Huergo, L.F; Dixon, R. The Emergence of 2-Oxoglutarate as a Master Regulator Metabolite. Microbiol. Mol. Biol. Rev. 2015, 79, 419-435. [CrossRef] [PubMed]

2. Forchhammer, K.; Luddecke, J. Sensory properties of the PII signalling protein family. FEBS J. 2016, 283, 425-437. [CrossRef]

3. Santos, A.R.S.; Gerhardt, E.C.M.; Parize, E.; Pedrosa, F.O.; Steffens, M.B.R.; Chubatsu, L.S.; Souza, E.M.; Passaglia, L.M.P.; Sant'Anna, F.H.; de Souza, G.A.; et al. NAD+ biosynthesis in bacteria is controlled by global carbon/nitrogen levels via PII signaling. J. Biol. Chem. 2020, 295, 6165-6176. [CrossRef] [PubMed]

4. Gerhardt, E.C.M.; Parize, E.; Gravina, F.; Pontes, F.L.D.; Santos, A.R.S.; Araújo, G.A.T.; Goedert, A.C.; Urbanski, A.H.; Steffens, M.B.R.; Chubatsu, L.S.; et al. The Protein-Protein Interaction Network Reveals a Novel Role of the Signal Transduction Protein PII in the Control of c-di-GMP Homeostasis in Azospirillum brasilense. mSystems 2020, 5, e00817-20. [CrossRef] [PubMed]

5. Forchhammer, K.; Selim, K.A. Carbon/nitrogen homeostasis control in cyanobacteria. FEMS Microbiol. Rev. 2019, 41, 33-53. [CrossRef]

6. Orthwein, T.; Scholl, J.; Spät, P.; Lucius, S.; Koch, M.; Macek, B.; Hagemann, M.; Forchhammer, K. The novel PII -interactor PirC identifies phosphoglycerate mutase as key control point of carbon storage metabolism in cyanobacteria. Proc. Natl. Acad. Sci. USA 2021, 118, e2019988118. [CrossRef]

7. Hsieh, M.H.; Lam, H.M.; van de Loo, F.J; Coruzzi, G. A PII-like protein in Arabidopsis: Putative role in nitrogen sensing. Proc. Natl. Acad. Sci. USA 1998, 95, 13965-13970. [CrossRef]

8. Sugiyama, K.; Hayakawa, T.; Kudo, T.; Ito, T.; Yamaya, T. Interaction of N-Acetylglutamate Kinase with a PII-Like Protein in Rice. Plant Cell Physiol. 2004, 45, 1768-1778. [CrossRef] [PubMed]

9. Chen, Y.M.; Ferrar, T.S.; Lohmeier-Vogel, E.M.; Morrice, N.; Mizuno, Y.; Berenger, B.; Ng, K.K.; Muench, D.G.; Moorhead, G.B. The PII signal transduction protein of Arabidopsis thaliana forms an arginine-regulated complex with plastid N-acetyl glutamate kinase. J. Biol. Chem. 2006, 281, 5726-5733. [CrossRef]

10. Zhang, Z.; Hu, B.; Chu, C. Towards understanding the hierarchical nitrogen signalling network in plants. Curr. Opin. Plant Biol. 2020, 55, 60-65. [CrossRef]

11. Feria Bourrellier, A.B.; Ferrario-Mery, S.; Vidal, J.; Hodges, M. Metabolite regulation of the interaction between Arabidopsis thaliana PII and N-acetyl-l-glutamate kinase. Biochem. Biophys. Res. Commun. 2009, 387, 700-704. [CrossRef]

12. Feria Bourrellier, A.B.; Valot, B.; Guillot, A.; Ambard-Bretteville, F.; Vidal, J.; Hodges, M. Chloroplast acetyl-CoA carboxylase activity is 2-oxoglutarate-regulated by interaction of PII with the biotin carboxyl carrier subunit. Proc. Natl. Acad. Sci. USA 2010, 107, 502-507. [CrossRef] [PubMed]

13. Chellamuthu, V.R.; Ermilova, E.; Lapina, T.; Luddecke, J.; Minaeva, E.; Herrmann, C.; Hartmann, M.D.; Forchhammer, K. A widespread glutamine-sensing mechanism in the plant kingdom. Cell 2014, 159, 1188-1199. [CrossRef] 
14. Selim, K.A.; Ermilova, E.; Forchhammer, K. From cyanobacteria to Archaeplastida: New evolutionary insights into PII signalling in the plant kingdom. New Phytol. 2020, 227, 722-731. [CrossRef] [PubMed]

15. Hauf, W.; Schmid, K.; Gerhardt, E.C.M.; Huergo, L.F.; Forchhammer, K. Interaction of the Nitrogen Regulatory Protein GlnB (PII) with Biotin Carboxyl Carrier Protein (BCCP) Controls Acetyl-CoA Levels in the Cyanobacterium Synechocystis sp. PCC 6803. Front. Microbiol. 2016, 7, 1700. [CrossRef] [PubMed]

16. Gerhardt, E.C.; Rodrigues, T.E.; Muller-Santos, M.; Pedrosa, F.O.; Souza, E.M.; Forchhammer, K.; Huergo, L.F. The bacterial signal transduction protein GlnB regulates the committed step in fatty acid biosynthesis by acting as a dissociable regulatory subunit of acetyl-CoA carboxylase. Mol. Microbiol. 2015, 95, 1025-1035. [CrossRef]

17. D’Apuzzo, E.; Valkov, V.T.; Parlati, A.; Omrane, S.; Barbulova, A.; Sainz, M.M.; Lentini, M.; Esposito, S.; Rogato, A.; Chiurazzi, M. PII Overexpression in Lotus japonicus Affects Nodule Activity in Permissive Low-Nitrogen Conditions and Increases Nodule Numbers in High Nitrogen Treated Plants. Mol. Plant-Microbe Interact. 2015, 28, 432-442. [CrossRef]

18. Parlati, A.; Valkov, V.T.; D’Apuzzo, E.; Alves, L.M.; Petrozza, A.; Summerer, S.; Costa, A.; Cellini, F.; Vavasseur, A.; Chiurazzi, M. Ectopic Expression of PII Induces Stomatal Closure in Lotus japonicus. Front. Plant Sci. 2017, 8, 1299. [CrossRef] [PubMed]

19. Ferrario-Mery, S.; Bouvet, M.; Leleu, O.; Savino, G.; Hodges, M.; Meyer, C. Physiological characterisation of Arabidopsis mutants affected in the expression of the putative regulatory protein PII. Planta 2005, 223, 28-39. [CrossRef]

20. Ferrario-Mery, S.; Besin, E.; Pichon, O.; Meyer, C.; Hodges, M. The regulatory PII protein controls arginine biosynthesis in Arabidopsis. FEBS Lett. 2006, 580, 2015-2020. [CrossRef]

21. Ferrario-Mery, S.; Meyer, C.; Hodges, M. Chloroplast nitrite uptake is enhanced in Arabidopsis PII mutants. FEBS Lett. 2008, 582, 1061-1066. [CrossRef] [PubMed]

22. Gent, L.; Forde, B.G. How do plants sense their nitrogen status? J. Exp. Bot. 2017, 68, 2531-2539. [CrossRef] [PubMed]

23. Liu, Y.; Duan, X.; Zhao, X.; Ding, W.; Wang, Y.; Xiong, Y. Diverse nitrogen signals activate convergent ROP2-TOR signaling in Arabidopsis. Dev. Cell 2021, 56, 1283-1295.e5. [CrossRef]

24. Nelson, B.K.; Cai, X.; Nebenfuhr, A. A multicolored set of in vivo organelle markers for co-localization studies in Arabidopsis and other plants. Plant J. 2007, 51, 1126-1136. [CrossRef]

25. Ishikawa-Ankerhold, H.C.; Ankerhold, R.; Drummen, G.P.C. Advanced Fluorescence Microscopy Techniques-FRAP, FLIP, FLAP, FRET and FLIM. Molecules 2012, 17, 4047-4132. [CrossRef]

26. Krupinska, K.; Oetke, S.; Desel, C.; Mulisch, M.; Schafer, A.; Hollmann, J.; Kumlehn, J.; Hensel, G. WHIRLY1 is a major organizer of chloroplast nucleoids. Front. Plant Sci. 2014, 5, 432. [CrossRef] [PubMed]

27. Izumi, M.; Wada, S.; Makino, A.; Ishida, H. The autophagic degradation of chloroplasts via rubisco-containing bodies is specifically linked to leaf carbon status but not nitrogen status in Arabidopsis. Plant Physiol. 2010, 154, 1196-1209. [CrossRef] [PubMed]

28. Wang, S.; Blumwald, E. Stress-induced chloroplast degradation in Arabidopsis is regulated via a process independent of autophagy and senescence-associated vacuoles. Plant Cell 2014, 26, 4875-4888. [CrossRef]

29. Chiba, A.; Ishida, H.; Nishizawa, N.K.; Makino, A.; Mae, T. Exclusion of ribulose-1,5-bisphosphate carboxylase/oxygenase from chloroplasts by specific bodies in naturally senescing leaves of wheat. Plant Cell Physiol. 2003, 44, 914-921. [CrossRef]

30. Ishida, H.; Yoshimoto, K.; Izumi, M.; Reisen, D.; Yano, Y.; Makino, A.; Ohsumi, Y.; Hanson, M.R.; Mae, T. Mobilization of rubisco and stroma-localized fluorescent proteins of chloroplasts to the vacuole by an ATG gene-dependent autophagic process. Plant Physiol. 2008, 148, 142-155. [CrossRef]

31. ONO, Y.; WADA, S.; IZUMI, M.; MAKINO, A.; ISHIDA, H. Evidence for contribution of autophagy to Rubisco degradation during leaf senescence in Arabidopsis thaliana. Plant Cell Environ. 2013, 36, 1147-1159. [CrossRef] [PubMed]

32. Üstün, S.; Hafrén, A.; Liu, Q.; Marshall, R.S.; Minina, E.A.; Bozhkov, P.V.; Vierstra, R.D.; Hofius, D. Bacteria Exploit Autophagy for Proteasome Degradation and Enhanced Virulence in Plants. Plant Cell 2018, 30, 668-685. [CrossRef] [PubMed]

33. Perello, C.; Llamas, E.; Burlat, V.; Ortiz-Alcaide, M.; Phillips, M.A.; Pulido, P.; Rodriguez-Concepcion, M. Differential Subplastidial Localization and Turnover of Enzymes Involved in Isoprenoid Biosynthesis in Chloroplasts. PLoS ONE 2016, 11, e0150539. [CrossRef] [PubMed]

34. Llamas, E.; Pulido, P.; Rodriguez-Concepcion, M. Interference with plastome gene expression and Clp protease activity in Arabidopsis triggers a chloroplast unfolded protein response to restore protein homeostasis. PLoS Genet. 2017, 13, e1007022. [CrossRef] [PubMed]

35. Baud, S.; Feria Bourrellier, A.B.; Azzopardi, M.; Berger, A.; Dechorgnat, J.; Daniel-Vedele, F.; Lepiniec, L.; Miquel, M.; Rochat, C.; Hodges, M.; et al. PII is induced by WRINKLED1 and fine-tunes fatty acid composition in seeds of Arabidopsis thaliana. Plant J. 2010, 64, 291-303. [CrossRef]

36. Llebrés, M.T.; Pascual, M.B.; Valle, C.; de la Torre, F.N.; Valderrama-Martin, J.M.; Gómez, L.; Avila, C.; Cánovas, F.M. Structural and Functional Characteristics of Two Molecular Variants of the Nitrogen Sensor PII in Maritime Pine. Front. Plant Sci. 2020, 11, 823. [CrossRef]

37. Espinosa, J.; Labella, J.I.; Cantos, R.; Contreras, A. Energy drives the dynamic localization of cyanobacterial nitrogen regulators during diurnal cycles. Environ. Microbiol. 2018, 20, 1240-1252. [CrossRef]

38. Beez, S.; Fokina, O.; Herrmann, C.; Forchhammer, K. N-acetyl-L-glutamate kinase (NAGK) from oxygenic phototrophs: P(II) signal transduction across domains of life reveals novel insights in NAGK control. J. Mol. Biol. 2009, 389, 748-758. [CrossRef] 
39. Forcada-Nadal, A.; Llacer, J.L.; Contreras, A.; Marco-Marin, C.; Rubio, V. The PII-NAGK-PipX-NtcA Regulatory Axis of Cyanobacteria: A Tale of Changing Partners, Allosteric Effectors and Non-covalent Interactions. Front. Mol. Biosci. 2018, 5, 91. [CrossRef]

40. Rozbeh, R.; Forchhammer, K. Split NanoLuc technology allows quantitation of interactions between PII protein and its receptors with unprecedented sensitivity and reveals transient interactions. Sci. Rep. 2021, 11, 12535. [CrossRef]

41. Rodriguez-Concepcion, M.; D'Andrea, L.; Pulido, P. Control of plastidial metabolism by the Clp protease complex. J. Exp. Bot. 2018, 70, 2049-2058. [CrossRef] [PubMed]

42. Watzer, B.; Spät, P.; Neumann, N.; Koch, M.; Sobotka, R.; Macek, B.; Hennrich, O.; Forchhammer, K. The Signal Transduction Protein PII Controls Ammonium, Nitrate and Urea Uptake in Cyanobacteria. Front. Microbiol. 2019, 10, 1428. [CrossRef] [PubMed]

43. Huang, J.; Chen, D.; Yan, H.; Xie, F.; Yu, Y.; Zhang, L.; Sun, M.; Peng, X. Acetylglutamate kinase is required for both gametophyte function and embryo development in Arabidopsis thaliana. J. Integr. Plant Biol. 2017, 59, 642-656. [CrossRef]

44. Shivaiah, K.-K.; Ding, G.; Upton, B.; Nikolau, B.J. Non-Catalytic Subunits Facilitate Quaternary Organization of Plastidic Acetyl-CoA Carboxylase1. Plant Physiol. 2019, 182, 756-775. [CrossRef] [PubMed]

45. Farmaki, T.; Sanmartín, M.; Jiménez, P.; Paneque, M.; Sanz, C.; Vancanneyt, G.; León, J.; Sánchez-Serrano, J.J. Differential distribution of the lipoxygenase pathway enzymes within potato chloroplasts. J. Exp. Bot. 2007, 58, 555-568. [CrossRef]

46. Mueller, S.J.; Lang, D.; Hoernstein, S.N.W.; Lang, E.G.E.; Schuessele, C.; Schmidt, A.; Fluck, M.; Leisibach, D.; Niegl, C.; Zimmer, A.D.; et al. Quantitative Analysis of the Mitochondrial and Plastid Proteomes of the Moss Physcomitrella patens Reveals Protein Macrocompartmentation and Microcompartmentation. Plant Physiol. 2014, 164, 2081-2095. [CrossRef]

47. Sweetlove, L.J.; Fernie, A.R. The role of dynamic enzyme assemblies and substrate channelling in metabolic regulation. Nat. Commun. 2018, 9, 2136. [CrossRef]

48. Clough, S.J.; Bent, A.F. Floral dip: A simplified method for Agrobacterium -mediated transformation of Arabidopsis thaliana. Plant J. 1998, 16, 735-743. [CrossRef]

49. Schöb, H.; Kunz, C.; Meins Jr, F. Silencing of transgenes introduced into leaves by agroinfiltration: A simple, rapid method for investigating sequence requirements for gene silencing. Mol. Gen. Genet. MGG 1997, 256, 581-585. [CrossRef]

50. Sparkes, I.A.; Runions, J.; Kearns, A.; Hawes, C. Rapid, transient expression of fluorescent fusion proteins in tobacco plants and generation of stably transformed plants. Nat. Protoc. 2006, 1, 2019-2025. [CrossRef]

51. Hecker, A.; Wallmeroth, N.; Peter, S.; Blatt, M.R.; Harter, K.; Grefen, C. Binary 2in1 Vectors Improve in Planta (Co)localization and Dynamic Protein Interaction Studies. Plant Physiol. 2015, 168, 776-787. [CrossRef]

52. Grefen, C.; Städele, K.; Růžička, K.; Obrdlik, P.; Harter, K.; Horák, J. Subcellular Localization and In Vivo Interactions of the Arabidopsis thaliana Ethylene Receptor Family Members. Mol. Plant 2008, 1, 308-320. [CrossRef] [PubMed]

53. Blatt, M.R.; Grefen, C. Applications of fluorescent marker proteins in plant cell biology. Methods Mol. Biol. 2014, 1062, 487-507. [CrossRef] [PubMed]

54. Sweere, U.; Eichenberg, K.; Lohrmann, J.; Mira-Rodado, V.; Bäurle, I.; Kudla, J.; Nagy, F.; Schäfer, E.; Harter, K. Interaction of the Response Regulator ARR4 with Phytochrome B in Modulating Red Light Signaling. Science 2001, 294, 1108-1111. [CrossRef]

55. Wanke, D.; Hohenstatt, M.L.; Dynowski, M.; Bloss, U.; Hecker, A.; Elgass, K.; Hummel, S.; Hahn, A.; Caesar, K.; Schleifenbaum, F.; et al. Alanine Zipper-Like Coiled-Coil Domains Are Necessary for Homotypic Dimerization of Plant GAGA-Factors in the Nucleus and Nucleolus. PLoS ONE 2011, 6, e16070. [CrossRef] [PubMed]

56. Karimi, M.; Inzé, D.; Depicker, A. GATEWAYTM vectors for Agrobacterium-mediated plant transformation. Trends Plant Sci. 2002, 7, 193-195. [CrossRef]

57. Curtis, M.D.; Grossniklaus, U. A Gateway Cloning Vector Set for High-Throughput Functional Analysis of Genes in Planta. Plant Physiol. 2003, 133, 462-469. [CrossRef]

58. Grefen, C.; Blatt, M.R. A 2in1 cloning system enables ratiometric bimolecular fluorescence complementation (rBiFC). Biotechniques 2012, 53, 311-314. [CrossRef]

59. Ladwig, F.; Dahlke, R.I.; Stührwohldt, N.; Hartmann, J.; Harter, K.; Sauter, M. Phytosulfokine Regulates Growth in Arabidopsis through a Response Module at the Plasma Membrane That Includes CYCLIC NUCLEOTIDE-GATED CHANNEL17, H+-ATPase, and BAK1. Plant Cell 2015, 27, 1718-1729. [CrossRef]

60. Schindelin, J.; Arganda-Carreras, I.; Frise, E.; Kaynig, V.; Longair, M.; Pietzsch, T.; Preibisch, S.; Rueden, C.; Saalfeld, S.; Schmid, B.; et al. Fiji: An open-source platform for biological-image analysis. Nat. Methods 2012, 9, 676-682. [CrossRef] 